\title{
Reflection on-line or off-line: the role of learning technologies in encouraging students to reflect
}

\author{
Jane K. Seale ${ }^{\mathrm{a}, *}$, Alan J. Cann ${ }^{\mathrm{b}}$ \\ ${ }^{a}$ School of Occupational Therapy and Physiotherapy, University of Southampton, Southampton, UK \\ ${ }^{\mathrm{b}}$ Department of Microbiology and Virology, University of Leicester, Leicester, UK
}

\begin{abstract}
This paper presents case studies that describe the experiences of the two authors in trying to use learning technologies to facilitate reflective thinking in their students. At the University of Leicester, a Web-based biology tutorial called 'How Now Mad Cow', which covers the topics of bovine spongiform encephalopathy and a new variant Creutzfeldt-Jakob disease (nvCJD). At the University of Southampton, a web-based hyper-mail discussion list to support teaching on a first year psychosocial science module for occupational therapy and physiotherapy students has been established. In both examples, the tutors had attempted to create a learning environment that would engage students in the learning experience and facilitate reflection by helping them to create meaning from the learning experience and see things in a different way. The evaluation data from both case studies provides some evidence that the learning technologies helped to facilitate reflection for some students. However, the evidence for reflection is not overwhelming and the data provides some evidence that four key factors may have influenced how successful the use of learning technologies were in facilitating reflection. These factors are the way the learning technology is used, the nature of the student groups, the role of the tutor and student preferences for 'off-line reflection'. These are discussed and ways forward are identified. (C) 2000 Elsevier Science Ltd. All rights reserved.
\end{abstract}

Keywords: Adult learning; Computer-mediated communication; Lifelong learning

\footnotetext{
* Corresponding author.

E-mail address: jks1@soton.ac.uk (J.K. Seale).
}

0360-1315/00/\$ - see front matter (C) 2000 Elsevier Science Ltd. All rights reserved.

PII: S0360-1315(99)00052-4 


\section{Introduction}

There is a growing aspiration that higher education should be involved in transforming students into 'critical reflective thinkers' able to cope with a rapidly changing world (Harvey \& Knight, 1996). At the heart of most definitions of critical reflective thinking is the notion of creating a meaning or conceptualization from a learning experience that enables a learner to see things in a different way (Kolb, 1984, Brockbank \& McGill, 1998).

A learner may try to create meaning from the learning experience by trying to re-frame the experience. According to Mackinnon (1993) and Smith (1994), reframing involves re-examining the problem (learning experience) from one or more theoretical platforms. Reframing occurs several times with counter examples being constructed and contrasted. In the final phase, a new conclusion from the reframing is formulated and a new implication is often derived. The initial problem is resolved but new problems may be highlighted which require the reflective cycle to continue.

A learner may try to create meaning after or during the learning experience. Schon (1987) distinguished between reflection in action and reflection on action. Reflecting on action is the thinking that takes place after an event or experience. It is thinking back on what we have done in order to discover how the knowledge we put into action may have contributed to an unexpected outcome. Alternatively, we may reflect in the middle of an experience without interrupting it. Our thinking serves to reshape what we are doing while we are doing it.

In addition to producing definitions of reflection, writers have discussed how reflection can be facilitated. For example, Laurillard (1993) argues that reflection occurs in a goal-actionfeedback cycle, whereby students link feedback on their actions to the topic goal. Reflection can therefore be facilitated if teachers discuss and negotiate with students what the goals might be, give feedback (adapt a student's perception and enable them to experience it from different perspectives) and give students opportunities to reflect on their experiences and to internalize them. This process of discussion and negotiation between teacher and student may be defined as a reflective dialogue (Brockbank \& McGill, 1998).

\section{Using learning technologies to facilitate reflection}

Computer based tutorials are frequently cited as offering opportunities for reflection (Seale, 1997) because in theory it is possible for goals to be set for the use of the tutorial and feedback can be given when the student is using the tutorial. Laurillard (1993), for example, saw the potential of intelligent tutoring systems for encouraging reflection because such systems can keep a record of student experience as far as performance on tasks is concerned. They can therefore call on a great deal of information pertinent to the task of reflecting on what has been achieved in relation to the overall goal.

There is a growing acceptance that a reflective dialogue could be supported using computermediated communication. With an emphasis on conversation, McLoughlin and Oliver (1998) consider that learning around computers can be facilitated through collaborative learning where students interact with one another (peer interaction) and with teachers. An example of 
such learning might be the use of computer-based tutorials that employ e-mail as a communication tool (Light, Colbourn \& Light, 1997). They have the capacity to encourage reflection by using conversation and collaboration as tools for helping students to adapt and reframe ideas.

This paper will present two case studies that describe the experiences of the two authors in trying to use learning technologies to facilitate reflective thinking in their students. In order to explore whether or not the two different uses of learning technologies were successful in facilitating reflection, evaluation data will be presented that addresses the question: Did the students try to create meaning from the learning experience and see things in a different way?

\section{Case study one: a biology on-line tutorial}

The Web-based tutorial "How Now Mad Cow" covers the topics bovine spongoform encephalopathy (BSE) and Crentz fedlt-Jaocb disease (CJD) (Cann \& Seale, 1997). Deliberately contentious subject matter (the relationship BSE and nvCJD (new variant crentzfedlt Jacob disease)) was chosen for this tutorial http://www-micro.msb.le.ac.uk/ tutorials/cow/cow1.html. Cann and Seale (1999) considered that the students would be encouraged to consider and engage in the learning experience through the use of role play/ fictional elements and humour. An example of the use of fiction is an imaginary but accurately researched account of the death of a New Guinea shaman from 'Kuru' in 1949 http://www-micro.msb.le.ac.uk/Tutorials/cow/cow3.html. It was also considered that students would be encouraged to try and create meaning from the learning experience through the use of an on-line discussion forum and open questions such as, 'What is the truth?' and 'You decide..' http://www-micro.msb.le.ac.uk/tutorials/cow/cow2.html). The online tutorials were not used as part of formal teaching, but rather as open learning materials in what is intended to be a resource-rich environment, incorporating open access to the Web (Cann, 1997).

\subsection{Evaluation methodology}

In order to evaluate the success of the on-line tutorial and assess whether it did actually encourage users to reflect, the final page of the tutorial consisted of a detailed online questionnaire. A number of questions were asked of users, including what they liked least and best about the tutorial. However, the questions that were posed specifically to gain an insight into reflection were:

- How did they first find the tutorial? (reason for using tutorial-goals)

- Did the tutorial influence their thinking afterwards (using information to change goals or perceptions-feedback)

- What did students do in the intervals between using the tutorial? (taking time out from material to interpret, organize and explore the experience of using the tutorial)

- Did they take part in the "Discussion Forum" (engaging in a reflective dialogue) 
The responses to the on-line questionnaire were placed in a log file that was analysed using Microsoft Excel. A total of 105 questionnaire responses (duplicates excluded) were collected and analysed, a response rate of $17 \%$.

\subsection{Evidence that the learners tried to create meaning from the experience}

The authors anticipated that evidence for reframing could be found if users took a number of sessions to work through the tutorial and used the intervals to interpret, organize and explore the experience of using the tutorial. However, the majority of respondents $(77 \%)$ indicated that they worked through the tutorial in just one session. When asked why they had worked through the tutorial in just one session, four main reasons emerged. These were interest and curiosity, wanting an overview, familiarity and academic pressures such as, impending exams or needing material for an assignment.

Of the $23 \%$ of respondents who did take several sessions to work through the tutorial, a fair number used the intervals for purposes that could be interpreted as exploring or reframing the learning experience:

- finding and reading additional material (8/23);

- discussing the material with colleagues and tutors $(5 / 23)$;

- writing notes $(5 / 23)$;

- using the time for thinking or private reflection $(3 / 23)$.

Table 1

Reasons for not contributing to the on-line biology tutorial discussion

Reasons for not contributing to the Example comments

discussion

Lack of time $(n=22)$

I have a ton of homework left to do, sorry!

I have to get back to work.

Need to get on with my research paper, Sorry, not enough time.

I'm in a hurry.

Need time to think/may do in future Would like to consider the material further and develop my own position $(n=13)$ a little first.

I will go back to it. I was interested in all the information first.

Will return later, book-marked the spot.

I didn't have time, and I wanted to think about it for a while

Lack of ability/knowledge $(n=9)$

I do not consider myself an expert on the subject.

I'm no microbiologist!

Haven't figured out how to do that yet.

I am somewhat computer illiterate and do not often converse in this medium.

No interest or reason $(n=6)$

More interested in information than in discussing the subject with others.

No reason to contribute.

I don't know if it would be relevant

Other $(n=9)$

Didn't realize there was one.

There were not many good discussions. 
Although the discussion forum was accessed 145 times, only two responses were recorded in four months. Respondents indicated that there were four main reasons for not contributing to the discussion forum. These were lack of time, need of time to think or intent to come back to it in the future, lack of ability or knowledge and lack of interest or reason (see Table 1). The majority of respondents appear to have accessed the Mad Cow tutorial deliberately, with the specific goal of finding out more about BSE and related material. These respondents often made specific reference to virology, prions, BSE/CJD or immunology. Ninety-eight per cent of respondents indicated that they had learnt something new from the tutorial. A number of respondents also indicated that the tutorial had influenced their thinking and study behaviour afterwards. For example, they had:

- found and read additional material (25/66);

- discussed the material with colleagues and tutors $(22 / 66)$;

- wrote notes $(16 / 66)$;

- tried to solve the problems posed in the tutorials $(3 / 66)$.

\section{Case study two: a psychosocial sciences on-line discussion list}

In the spring term of 1999, a Web-based hyper-mail discussion list was set up at Southampton University to support teaching on a first year psychosocial science module, for occupational therapy and physiotherapy students. The students were required to access the discussion list in order to discuss one of the eight video case studies that had been shown in a lecture. The case studies within the video were of people being interviewed about their life experiences and how these had influenced their personal development. The topics raised in the interviews were topics that were covered in other parts of the module (e.g. bereavement, coping and self-efficacy).

It was considered that the use of the video case studies would engage students in the learning experience. Students were also allowed to work in self-chosen small groups as opposed to working individually, in an attempt to reduce the possibility of students opting out of the task. Five open questions were posed in order to encourage students to try and create meaning from the learning experience and enable them to make links with other parts of the course. It was anticipated that reading other groups' responses to the questions would enable the students to see the issues discussed from different perspectives.

\subsection{Evaluation methodology}

In order to evaluate the success of the on-line discussion list and assess whether it did actually encourage users to reflect, an anonymous two-page postal questionnaire was sent to all 124 first year students who attended the psychosocial sciences module. A number of questions were asked of users, including how much they worked as a group and how much as an individual. The questions that were posed specifically to gain an insight into reflection were:

- Did using the discussion list help you make links with other learning experiences? 
(interpreting, organizing and exploring the experience of using the tutorial)

- Did using the discussion list have an influence on your personal learning objectives, level of understanding or attitudes and beliefs? (using information to change goals or perceptionsfeedback)

A total of 47 completed questionnaires were returned at a response rate of $38 \%$. These questionnaires were analysed manually.

\subsection{Evidence that the learners tried to create meaning from the experience}

Fifty-nine percent (28/47) of respondents said that using the discussion list helped them to make links with other learning experiences. These respondents identified the following ways in which links could be made:

- links with other parts of the module (22/47);

- links with other parts of the degree course $(11 / 47)$;

- links with previous academic experiences (11/47);

- links with current or previous clinical experiences (10/47).

Table 2

Identified reasons why using the psychosocial science discussion list did or did not help students make links with other learning experiences

1. Why the psychosocial science list did help me make links: example comments

Links to clinical work $(n=5)$ Helps us to understand the feelings and emotions our clients may be experiencing in clinical settings.

It helped me to realise that when treating a person it is important to consider not only their physical problem but how they will react to it psychologically and everyone will react differently

Links to the module $(n=4) \quad$ Helped to pull together the theories

It helped me to link parts of the PSS module to real people and events

Links to the assessment

Helped with the assessment and aided me in finding a focus for analysis with my

$(n=2)$ own project

It helped me with my assessment essay as my subject had a lot ofmilestones and life events

2. Why the psychosocial science list did not help me make links: example comments

$\begin{array}{ll}\text { Clinical relevance }(n=3) & \begin{array}{l}\text { I have difficulty seeing how this is relevant to us when we are working as therapists } \\ \text { I couldn't see how this would help us in our profession }\end{array} \\ \text { Group dynamics and } & \text { Because so far with } 2 \text { days to go, only one other group has posed the responses to } \\ \text { contribution }(n=3) & \begin{array}{l}\text { I felt that some group members had more strong answers that I did not quite agree } \\ \text { with }\end{array} \\ \text { Dislike of computers }(n=4) & \text { Unless you are interested in "cybertalk" I can't really see the relevance of a } \\ \text { discussion group on the web, I prefer to do things face to face. } & \text { I find this way of learning very frustrating, and because this was the case, perhaps } \\ \text { this meant I was not open to making links with other learning experiences }\end{array}$


Table 3

Identified reasons why using the psychosocial science discussion list helped students see things in a different way

Example comments and identified themes

1. Personal learning objectives $(n=2) \quad$ The learning medium

- It forced me to explore the use of the Internet. It improved my computer skills (a personal goal).

- Introduced me to using the discussion list, which I hadn't used before, now I think it might well be useful.

2. Level of understanding $(n=10)$

Focus

- Actually sitting down with the task helped me to focus on the issues.

- Dealing the case studies helps to focus the learning.

Level of thinking

- Had to think more in order to answer the questions and relate back to prior lecture.

- Made me think in detail what was involved.

Use of case study

- It made me see how the patient-centred approach can be used the most effectively.

- Because it was linked to a case study it has increased my understanding.

3. Attitudes and beliefs $(n=3)$

Seeing different views and opinions

- By reading other groups comments, I realised that there were different ways of looking at people's lives. This challenged my views and beliefs and made me think about it more.

- It was useful to read other people's responses as they mentioned things that were either different or that we had not thought of. This wider perspective on how someone perceives a person influences and develops your own attitudes and beliefs.

The reasons students gave as to how the discussion list helped them to make links to other learning experiences included 'seeing' patients from a different perspective, putting theories together and providing a focus for the module assessment. For the $41 \%$ of students who said that using the discussion list had not helped them to make links to other learning experiences, the reasons given included failure to see the clinical relevance of the task, difficulties with group dynamics and a dislike of computers (see Table 2).

Thirty eight out of the 47 respondents indicated that using the discussion list had helped them to see things in a different way. Using the discussion list had an influence on:

- personal learning objectives (10/47);

- level of understanding (18/37);

- attitudes and beliefs (10/47).

Fifteen students gave explanations as to how the discussion list had helped them to see things in a different way. These explanations centred on changing objectives around using computers generally, the provision of a focus, deepening the level of thinking required, the use of case studies and the opportunity to read different views and opinions (see Table 3). Nine students 


\section{Table 4}

Identified reasons why using the psychosocial science discussion list did not help students see things in a different way

Example comments and identified themes

\begin{aligned} \hline 1. Personal learning objectives $(n=2) &$ The learning task \\ & - If the task was assessed I think it would have had a higher priority. \\ & - It wasn't clear what the learning objectives were supposed to be. \end{aligned}

2. Level of understanding $(n=4) \quad$ Not valuing student responses

- There wasn't anything to learn, only personal opinions.

- A lot of the responses were not really insightful.

\section{Preferring other forms of discussion}

- We are here because we want to care and work with people not have a discussion with a computer.

- I feel it is much more useful to discuss such personal and emotive topics face to face in small groups.

3. Attitudes and beliefs $(n=3)$

\section{Lack of 'controversy'}

- The views were not challenging or different from mine.

- Perhaps if our case study had been more "controversial" in some way it may have provoked more differing views.

gave explanations as to how the discussion list had not helped them to see things in a different way. These explanations centred on the nature of the learning task, not valuing student responses, preferring other forms of discussion and a perceived lack of controversy in the discussion (see Table 4).

\section{Discussion}

The evaluation data from both case studies provides some evidence that the learning technologies helped to facilitate reflection for some students. For the biology on-line tutorial, there was evidence that a small group of users engaged with the material and tried to create meaning from the experience, by taking time out from the material, in order to discuss it with colleagues or think privately. Some respondents also indicated that the tutorial had influenced their thinking or changed their perceptions. For the psychosocial sciences discussion list, there was evidence that a small group of students engaged with the case studies and through discussing them were able to make links with other learning experiences or see things in different ways. The evidence for reflection is not overwhelming however, and the data provide some evidence for a number of factors that may influence how successful learning technologies are in facilitating reflection. These factors are:

- The way the learning technology is used

- The nature of the student groups 
- The role of the tutor

- Preference for 'off-line' reflection

\subsection{The way the learning technology is used}

The two case studies reported used learning technologies in two very different ways. The biology on-line tutorial was not used as part of formal teaching but as open learning material that anyone could access if they wished. The psychosocial science discussion list was used as part of formal teaching and students were required to use it as part of directed study. The focus of the biology on-line tutorial was on allowing students to gain information while offering them an opportunity to apply, discuss and reflect on it. In other words, the discussion list may have been seen as a 'secondary' part of the learning experience. For the psychosocial science for example, the discussion list was the primary part of the learning experience. It is possible therefore, that the way both case studies used learning technologies may have had an influence on the level and amount of reflection they facilitated.

For the biology on-line tutorial, students may have been encouraged to value gaining information above reflecting on information. One of the strengths of the biology on-line tutorial is that it offers students a huge resource base of information regarding BSE and related material. Indeed, the evaluation results revealed that the majority of respondents appear to have accessed the 'How Now Mad Cow' tutorial deliberately, with the specific goal of finding out more about BSE and related material. However the 'pull' or attraction of the information held within the tutorial may have weakened the potential for encouraging reflection. If the main focus of the tutorial, is the information that it contains, then it may be more competency-based as opposed to reflective practice-based. Seale (1997) argued that competency based materials encourage students to focus on the knowledge they can gain and be tested on rather than how they reframe and conceptualize the information.

For the psychosocial science on-line discussion list, use of the discussion list was the primary purpose and a compulsory requirement for the students. Students have probably accessed the discussion list because they had to and not because they wanted to. For some students, the compulsory nature of the task will not have influenced their learning experience, for others there is evidence to suggest that making the task compulsory may have had a negative influence on some students' learning experience. For example, the data in Table 2 suggests that making the task compulsory masked its relevance for some students and led some students to adopt very strategic approaches such as, leaving it close to the deadline to post responses to the list. Many educators have struggled with the dilemma of making use of computer-mediated communication compulsory. Lee, Dineen and McKendree (1997), for example, compared compulsory and non-compulsory lists and found that for non-compulsory lists, contributions were knowledge based, arising out of students' interest, whereas for compulsory lists students restricted their questions to a more shallow text-based level. Compulsory tasks on discussion lists may reduce the quality of learning experience for some students, and this could in turn influence the quality of their contributions. 


\subsection{The nature of the user groups}

There is some evidence to suggest that the nature of the two user groups may have influenced how they used the learning technologies in both case studies. The computer skills/ attitudes and level of education of both groups could be factors that influenced whether or not students engaged in the task.

For the on-line biology tutorial, there is evidence that lack of technical ability prevented some learners from contributing to the discussion forum (see Table 1). For the psychosocial science on-line tutorial, there is evidence that a dislike of computers prevented some learners from enjoying or benefiting from the learning experience (see Table 2). Other studies have also found that technical ability can influence students' contribution to discussions. For example, in reporting the use of 'skywriting' with second year psychology students, Light et al. (1997) reported that a small group of computer-proficient (mostly male) students used the 'skywriting' facility. Dislike of computers or technophobia is not an unusual phenomenon and may explain why some students using the psychosocial science discussion list did not appear to be reflecting on the learning. However, further exploration is necessary in order to identify whether these students were really expressing a dislike of computers or were trying to find a 'safe way' of expressing annoyance at the task being made compulsory.

The level of education for both groups was quite different. As the on-line biology tutorial was used as open-learning material, anyone, from undergraduate to postgraduate student, could access the material. Those who accessed the discussion may have therefore felt uncomfortable contributing, as they may be unsure of the level that everyone else was operating at, and so did not want to appear unknowledgeable (see Table 1). The psychosocial science discussion list was used with a group of first year students who knew each other and worked together to produce responses for the list. It could be possible to argue therefore that this group of users would be less frightened of using the discussion list and therefore would have more opportunity to engage in the material and reflect on it. Interestingly however, there is evidence from the data that some students did not value their colleague's responses or complained that responses were so similar that there was no 'controversy' (see Table 4). Having a more mixed group of students in terms of level of education and subject may help to overcome such complaints. However, Light et al. (1997) report better results when 'skywriting' was used with third year students, all studying the same specialised subject. They likened the experience to 'shared commentaries'. It may be useful to explore in more detail the influence that the nature of student groups has on the use of discussion lists.

\subsection{Role of tutors}

In order to facilitate reflection, both Laurillard (1993) and McLoughlin and Oliver (1998) argue that tutors need to play a pivotal role in discussing and negotiating with students what their goals might be in using learning technologies and clarifying expectations for use. In discussing the requirements for an effective reflective dialogue, Brockbank and McGill (1998) argue that the dialogue will:

- enable rather than disable (use power in the relationship carefully), 
- be intentional and make clear what the purpose of the interaction is,

- explicitly draw attention to the process by which reflective practice can be undertaken.

By using their power as a lecturer and making use of the psychosocial science list compulsory, the tutor in the second case study may have engaged some of her students in a 'disabling dialogue' that may have hindered the potential for facilitating reflection. Some students in both case studies expressed ignorance regarding the purpose and relevance of the discussion list (see Tables 1 and 4). It is possible, therefore, that reflective thinking could be facilitated further if both tutors made the goals, purposes and expectations of using the discussion lists a lot more explicit. Placing such information in strategic places around the tutorial or posting messages to the discussion list at strategic times during the discussion could do this. One of the ways in which Brockbank and McGill argue that teachers can draw attention to the reflective process, is by modelling it. For the tutors in the two case studies, it is possible that they could model the reflective process by taking a more active part in the discussion list and posting responses that highlighted ways in which students could create meaning from the experience. This would have to be done very sensitively so that, students did not feel threatened by the tutor's 'superior' knowledge.

\subsection{Preference for 'off-line' reflection}

For the first case study, only two responses to the discussion forum were recorded. However, there is evidence to suggest that the on-line tutorial encouraged reflection in other ways. For example, $20 \%$ of those respondents, who took several sessions to work through the tutorial, used the interval to discuss the material with colleagues and tutors. Moreover, $33.3 \%$ of those respondents who indicated that the tutorial had influenced their thinking said that they had discussed the material with colleagues and tutors. While tutorial users may not wish to engage in on-line discussion, the tutorial seems to stimulate them to engage in 'off-line' discussion with others. This off-line reflection may be similar to 'reflection-on-action' as defined by Schon (1987). Thinking back on what we have done in order to discover how the knowledge we put into action may have contributed to an unexpected outcome.

For the second case study, there seems to be a distinct group of students who would prefer to take part in non-computer based discussion (see Tables 2 and 4). For these students it is possible that they would prefer their critical reflective thinking be facilitated through the use of another teaching medium. Students have different preferences for the way they learn and study, and the way we use learning technologies perhaps needs to reflect this (Valley, 1997).

\section{Conclusion}

The evaluation data from both case studies provides some evidence that the learning technologies helped to facilitate reflection for some students. The evidence for reflection is not overwhelming however, and the data provides some evidence for a number of factors that may influence how successful learning technologies are in facilitating reflection. In order to improve 
the potential for learning technologies to facilitate critical reflective thinking, the following issues need to be explored in more detail:

- Are students more likely to use learning technologies to engage in critical reflective thinking if they have a choice in whether or not they access them?

- Does having access to a large resource base of information divert students' attention away from opportunities for critical reflective thinking?

- Are students more likely to use learning technologies to engage in critical reflective thinking if other users are of a similar background to them?

- Does the use of learning technologies to facilitate critical reflective thinking suit a certain kind of student or learning preference?

- What methods can a tutor use to engage students in a reflective dialogue when using learning technologies?

- In what circumstances would it be beneficial to promote 'on-line' as opposed to 'off-line' reflection?

\section{References}

Brockbank, A., \& McGill, I. (1998). Facilitating reflective learning in higher education. Buckingham: Society for Research in Higher Education and Open University Press.

Cann, A. J. (1997). Working with the Web: a case study at the University of Leicester. Life Sciences Educational Computing, 8(2), 20-22.

Cann, A. J., \& Seale, J. (1997). How now mad cow: educating the reflective practitioner. Paper presented at the CUBE 97 Virtual Conference. (http://www.liv.ac.uk/ctibiol/vCUBE97/html/alan_cann.html.

Cann, A., \& Seale, J. (1999). Using computer based tutorials to encourage reflection. Journal of Biological Education, 33(3), 130-132.

Kolb, D. A. (1984). Experiential learning. Englewood Cliffs, NJ: Prentice Hall.

Harvey, L., \& Knight, P. (1996). Transforming higher education. Buckingham: Research in Higher Education and Open University Press.

Laurillard, D. (1993). Rethinking university teaching: a framework for the effective use of educational technology. London: Routledge.

Lee, J., Dineen, F., \& McKendree, J. (1997). Supporting student discussions: it isn't just talk. In D. Darina, \& I. Stanchev, Research on educational applications of information technologies (pp. 124-136). Sofia, Bulgaria: VIRTECH Ltd.

Light, P., Colbourn, C., \& Light, V. (1997). Computer mediated tutorial support for conventional university courses. Journal of Computer Assisted Learning, 13(4), 228-235.

Mackinnon, A. M. (1993). Detecting reflection-in-action among pre-service elementary science teachers. In E. Whitelegg, J. Thomas, \& S. Tresman, Challenges and opportunities for science education (pp. 44-60). London: Paul Chapman Publishing Ltd.

McLoughlin, C., \& Oliver, R. (1998). Maximising the language and learning link in computer learning environments. British Journal of Educational Technology, 29(2), 125-136.

Schon, D. (1987). Educating the reflective practitioner. London: Jossey Bass.

Seale, J. K. (1997). Developing CBL packages: a reflective practice approach in science education. In G. Chapman, Proceedings of Third International Computer Based Learning in Science Conference. Czech Republic: University of South Bohemia.

Smith, M. (1994). Local education: community, conversation, praxis. Buckingham: Open University Press.

Valley, K. (1997). Learning styles and courseware design. ALT-J, 5(2), 42-51. 